Revue d'histoire de l'Amérique française

DAV REVUE D.HISTOIRE DE L'AMÉRIQUE FRANÇAISE

\title{
Manifestations en hommage à Lionel Groulx à l'occasion du centenaire de sa naissance (1878-1978)
}

Volume 32, numéro 3, décembre 1978

Lionel Groulx, $100^{\mathrm{e}}$ anniversaire de sa naissance, 1878-1978

URI : https://id.erudit.org/iderudit/303726ar

DOI : https://doi.org/10.7202/303726ar

Aller au sommaire du numéro

Éditeur(s)

Institut d'histoire de l'Amérique française

ISSN

0035-2357 (imprimé)

1492-1383 (numérique)

Découvrir la revue

Citer ce document

(1978). Manifestations en hommage à Lionel Groulx à l'occasion du centenaire de sa naissance (1878-1978). Revue d'histoire de l'Amérique française, 32(3),

529-530. https://doi.org/10.7202/303726ar d'utilisation que vous pouvez consulter en ligne. 


\section{MANIFESTATIONS EN HOMMAGE Ā LIONEL GROULX Ā L'OCCASION DU CENTENAIRE DE SA NAISSANCE (1878-1978)}

le 12 janvier 1978: messe d'action de grâces en la chapelle du Séminaire de Québec;

le 16 janvier 1978 : ouverture de l'exposition des œuvres de Groulx à la Bibliothèque Nationale; lancement de HOMMAGE À LIONEL GROULX, sous la direction de Maurice Filion; table ronde composée de Fernand Dumont, Michel Brunet, Pierre Savard, Hélène-P. Baillargeon; le film : "L'homme de croyances ", émission "Sous le chêne de Mambré ", à Radio-Canada.

le 18 janvier 1978: À Radio-Québec dans la série "Visages ", reprise du film "Lionel Groulx ". le 21 janvier 1978 : Banquet en hommage à Lionel Groulx, au Motel Universel, à Québec. Près de 325 convives assistent au banquet et à la conférence de François-Albert Angers sur "Lionel Groulx et le nationalisme".

le 29 janvier 1978: À Radio-Canada, "L'homme de croyances", film présenté en primeur le 16 janvier à la Bibliothèque Nationale.

le 5 février 1978: Film d'une heure sur Lionel Groulx réalisé par Pierre Valcour de CinéMundo à l'émission "Les Beaux Dimanches", à Radio-Canada.

le 19 février 1978: Film de 30 minutes dans le cadre de l'émission "Regards sur le monde ", à Télé-Métropole à 22:00 hres.

le 20 février 1978: lancement du concours Lionel-Groulx, au secondaire et au collégial.

le 22 février 1978: Motion à l'Assemblée Nationale par le député Fabien Roy, pour commémorer unanimement le $100 \mathrm{e}$ anniversaire de naissance du chanoine Lionel Groulx.

le 27 février 1978 : conférence du Père Lucien Campeau, S.J., à la Société historique de Montréal, intitulée: "Lionel Groulx : l'homme enraciné à son milieu ".

le 13 avril 1978: Dans le cadre du 7e salon international du Livre de Québec, les Amis de Lionel Groulx et les Éditions Bellarmin procèdent au lancement d'une biographie populaire de Georges-Émile Giguère, S.J., intitulé : Lionel Groulx - biographie "Notre État français, nous l'aurons!" En même temps, les Éditions Leméac lançaient l'ouvrage posthume de Guy Frégault, Lionel Groulx tel qu'en lui-même.

le 16 avril 1978: Dans le cadre du 7e salon international du Livre, conférence de FrançoisAlbert Angers: "Lionel Groulx ". Projection du film de Ciné-Mundo à Québec.

le 17 avril 1978: Déjeûner marquant le lancement de la Campagne de souscription du Centre de recherche Lionel-Groulx (en histoire de l'Amérique française), en présence du premier ministre du Québec, Monsieur René Lévesque, sous la présidence de $\mathrm{M}$. Roland Giroux, président de la campagne. L'objectif est de 1 million de dollars et veut assurer la survie et l'épanouissement de l'œuvre de Lionel Groulx et du Centre de recherche qui portera son nom.

le 23 avril 1978: M. Pierre Tousignant rend hommage à Lionel Groulx, lors de la cérémonie de clôture du congrès de la Fédération des Sociétés d'histoire du Québec, à Pont-Viau, Ville de Laval. 
le 2 mai 1978: Dévoilement d'une plaque commémorative rappelant l'enseignement de Lionel Groulx au Collège de Valleyfield.

le 3 mai 1978: Les autorités municipales de Sallaberry-de-Valleyfield donnent le nom de Lionel Groulx à un parc, dans un nouveau développement de la Ville. Une réception civique suit la cérémonie.

les 2-3-4 mai 1978: Colloque au Collège de Valleyfield sur le thème : «Lionel Groulx, homme de combat. Nos questions et ses réponses ". Les conférenciers invités: Jean-Pierre Wallot, "La place de Lionel Groulx dans l'historiographie "; Madame Susan MannTrofimenkoff, "Quel modèle de société Lionel Groulx a-t-il proposé à ses concitoyens?"; François-Albert Angers, "Dans quelle mesure Lionel Groulx a-t-il influencé son milieu?». Des commentaires sont apportés par MM. Serge Gagnon, Robert Comeau, Stanley Ryerson, René Durocher, Jean-Louis Roy et Georges-Êmile Giguère.

le 4 mai 1978: Le Centre culturel de Saint-Lambert inaugure une exposition organisée par le Comité d'histoire Mouille-Pied.

le 23 mai 1978: Les Amis de Lionel Groulx et la Fédération des Sociétés d'histoire du Québec commémorent la mort de Lionel Groulx à l'Église Notre-Dame-des-Victoires de Québec.

le 28 mai 1978: À Vaudreuil, commémoration du 1le anniversaire de la mort du chanoine Lionel Groulx. Une messe concélébrée par l'évêque de Valleyfield, Monseigneur Robert Lebel, est suivie d'une cérémonie au cimetière : dépôts floraux, allocution de M. Jean-Pierre Wallot : "L'actualité de Lionel Groulx », suivie de M. Léandre Fradet, représentant Me Armand Maltais, président des Amis de Lionel Groulx.

mai 1978: Plusieurs expositions des oeuvres du chanoine Lionel Groulx ont lieu en divers endroits. Madame Juliette Rémillard se rend au Cegep Lionel-Groulx et à la Bibliothèqué Emile-Nelligan de Laval entretenir quelques invités de "Lionel Groulx ".

le 25 juin 1978: Concert donné par le Chour Vaudreuil-Soulanges, en hommage au chanoine Lionel Groulx, par la Ville de Vaudreuil, en l'église St-Michel de Vaudreuil.

le 29 juin 1978: Plaque au Colisée de Québec - Concert folklorique.

le 3 septembre 1978: Inauguration de la station de métro "Lionel-Groulx".

le 15 septembre 1978: Remise de "L'arbre de vie ", sculpture sur noyer séculaire de Joseph Rifesser, don de Monsieur Peter Casson, commissaire général de l'ONU, à la station de métro Lionel-Groulx.

le 12 octobre 1978: Le Conseil exécutif de l'Université de Montréal honore la mémoire de Lionel Groulx en donnant au Pavillon des Sciences sociales le nom de Pavillon LionelGroulx.

les 12-13-14 octobre 1978: Congrès de l'Institut d'histoire de l'Amérique française. Thème: "L'Amérique française à l'âge de Groulx".

le 27 octobre 1978: Remise des prix du Concours Lionel-Groulx dans le cadre du congrès de la Société des professeurs d'histoire du Québec, à Québec.

le 5 novembre 1978: Concert sacré en l'église des Saints-Martyrs canadiens, à Québec, par le Choeur lyrique d'Aubigny pour clôturer les manifestations des Amis de Lionel Groulx.

le 26 novembre 1978: Conférence de Georges-Émile Giguère, S.J., à Manchester, N.H. devant la Société historique franco-amércaine; "Lionel Groulx, son mythe et ses mythes". 